\title{
REFLEXÕES DE PROJETO EXTENSIONISTA: A TRAJETÓRIA NEGRA CONTADA E CANTADA POR MEIO DO SAMBA
}

\author{
Tatiane Kelly Pinto de Carvalho ${ }^{1}$, Maraísa Inês de Assis Martins ${ }^{2}$ \\ ${ }^{1}$ Doutoranda em Educação pela Universidade Federal de Ouro Preto - UFOP. Docente da Universidade do Estado de \\ Minas Gerais, Divinópolis, MG. E-mail: tkpcarvalho@yahoo.com.br \\ ${ }^{2}$ Graduanda em História pela Universidade do Estado de Minas Gerais - UEMG-Unidade Divinópolis.
}

\section{RESUMO}

A Lei no 10.639, sancionada em 2003, propiciou uma espécie de estímulo para a realização de projetos e trabalhos que contemplem um caráter educacional direcionado às inúmeras manifestações e expressões da diversificada cultura brasileira. Mediante isso, por meio de uma relação dialógica entre a Universidade e uma escola estadual de Divinópolis (MG), o referido projeto teve como objetivo, na formação dos discentes concluintes do Ensino Médio, resgatar a importância da cultura negra e a aceitação da diversidade na sociedade brasileira. Para isso, a pesquisa teve como foco central uma abordagem qualitativa e foi utilizado como método a revisão bibliográfica sobre a temática em questão e a efetivação de encontros e oficinas acerca do samba e seu contexto histórico-social, buscando elucidar as respectivas heranças da escravidão. A partir das discussões tecidas sobre o assunto, foi possível observar que uma grande parte dos discentes se mostrou sensibilizada sobre assuntos que incluíam o preconceito, a violência e o racismo ainda tão vigentes na sociedade. Além disso, ficou nítido que tais debates e discussões podem auxiliar e colaborar em uma reafirmação da postura dos alunos no que diz respeito à cultura negra. Conclui-se que o projeto extensionista colaborou para que os alunos concluintes do Ensino Médio pudessem constituir uma diferenciada percepção social da cultura afrodescendente e, ao mesmo tempo, contribuiu para repensar em temáticas tão caras, como a aceitação do outro e suas respectivas diferenças.

Palavras-chave: Cultura negra. Ensino médio. Lei no 10.639. Samba.

\section{EXTENSIONIST PROJECT REFLECTIONS: THE BLACK TRAJECTORY TOLD AND SUNG BY SAMBA}

\begin{abstract}
ABSTRAT
Law no 10,639, sanctioned in 2003, provided a kind of stimulus for the accomplishment of projects and works that contemplate an educational character directed to the innumerable manifestations and expressions of the diverse Brazilian culture. Thus, through a dialogical relationship between the University and a state school of Divinópolis (MG), this project aimed, in the formation of high school graduates, to rescue the importance of black culture and the acceptance of diversity in Brazilian society. For this, the research focused on a qualitative approach and we used as a method the literature review on the theme in question and the holding of meetings and workshops about samba and its historical-social context, seeking to elucidate the respective inheritances of slavery. From the discussions on the subject, it was possible to observe that a large part of the students was sensitized on subjects that include prejudice, violence and racism still so prevalent in society. Moreover, it was clear that such debates and discussions can assist and collaborate in a reaffirmation of the students' attitude regarding black culture. It is concluded that the extension project collaborated so that high school graduates could constitute a different social perception of African descent and, at the same time, helped to rethink such expensive topics as the acceptance of the other and their respective differences.
\end{abstract}

Keywoeds: Black culture. High school. Law no 10,639. Samba. 


\section{REFLEXIONES DEL PROYECTO EXTENSIONISTA: LA TRAYECTORIA NEGRA CONTADA Y CANTADA PORSAMBA}

\section{RESUMEN}

Ley no 10.639 , sancionada en 2003, proporcionó una especie de estímulo para larealización de proyectos y obras que contemplanun carácter educativo dirigido a lasinnumerablesmanifestaciones y expresiones de la diversa cultura brasileña. Así, a través de una relación dialógica entre laUniversidad y una escuela estatal de Divinópolis (MG), este proyectotuvo como objetivo, enlaformación de graduados de secundaria, rescatarlaimportancia de cultura negra y laaceptación de ladiversidadenlasociedadbrasileña. Para esto, la investigación se centró en una cualitativa y utilizamos como método larevisión de la literatura sobre el tema encuestión y lacelebración de reuniones y talleres sobre la samba y su contexto histórico-social, buscando dilucidar las respectivas herencias de laesclavitud. A partir de lasdiscusiones sobre el tema, fueposible observar que una gran parte de losestudiantesestaba sensibilizada sobre temas que incluyenprejuicios, violencia y racismo que aúnprevalecenenlasociedad. Además, estaba claro que tales debates y discusionespuedenayudar y colaborar en una reafirmación de laactitud de losestudiantesconrespecto a la cultura negra. Se concluye que elproyecto de extensióncolaboró para que los graduados de secundaria pudieran constituir una percepción social diferente de laascendencia africana $y$, al mismotiempo, ayudaron a repensar temas tan caros como laaceptacióndelotro y sus respectivas diferencias.

Palabras clave: Cultura negra. Escuela secundaria. Ley $n^{\circ}$ 10.639. Samba.

\section{QUESTÕES INTRODUTÓRIAS}

Sancionada em 2003, a Lei no $10.639^{1}$ pode ser considerada um estímulo à realização de projetos de caráter educacional direcionados às distintas manifestações e expressões mais autênticas e diversificadas da cultura brasileira. Diante desse cenário ilustrado, contar a história do samba é a consolidação de uma possibilidade em que os sujeitos podem conhecer e apreciar a musicalidade brasileira oriunda de raízes africanas. Cabe ressaltar que o presente projeto foi executado, no ano de $2018^{2}$, em consonância com as Diretrizes Curriculares Nacionais para a Educação das Relações Étnico-Raciais bem como para o Ensino de História e Cultura Afro-Brasileira e Africanas, isto é, a necessidade de questionar "relações étnico-raciais baseadas em preconceitos que desqualificam os negros e salientam estereótipos depreciativos, palavras e atitudes que, velada ou explicitamente violentas, expressam sentimentos de superioridade em

\footnotetext{
${ }^{1}$ Altera a Lei no 9.394 , de 20 de dezembro de 1996, que estabelece as diretrizes e bases da educação nacional, para incluir no currículo oficial da Rede de Ensino a obrigatoriedade da temática "História e Cultura Afro-Brasileira", e dá outras providências. Disponível em: http://www.planalto.gov.br/ccivil_03/leis/2003/L10.639.htm. Acesso em 20/05/2019.

${ }^{2}$ Projeto de Extensão: “A trajetória negra contada e cantada por meio do samba", contemplado e financiado pelo Programa de apoio a projetos de extensão PAEX- Edital N 01/2018. Duração no período de abril a novembro de 2018.
}

relação aos negros, próprios de uma sociedade hierárquica e desigual" (BRASIL, 2004, p. 12).

Nessa perspectiva, a intenção do projeto foi contribuir para o (re) conhecimento da história do povo negro no Brasil, assim como seu papel relevante e crucial para a constituição da identidade e formação do povo e da sociedade brasileira. Não menos importante, buscou-se ressaltar a percepção de valorização das diferenças, o rompimento de preconceitos, bem como visões negativas sobre a cultura afrobrasileira e, principalmente, propiciar a valorização e enaltecimento da música popular brasileira, tendo como destaque o samba.

Respaldando-se em Ferreira et al. (2003), a história do negro sempre foi mal contada nos livros; não era comum a menção da luta contra a escravidão e a resistência dos africanos e descendentes, bem como os heróis eram anônimos, desconsiderando que, desde a chegada em território brasileiro, os negros construíram respeitáveis patrimônios culturais da humanidade.

No que se refere à valorização da cultura negra, os jovens precisam dialogar sobre a importância da cultura africana no Brasil, pois "contribui para o desenvolvimento de uma consciência crítica, pautada na reflexão dos seus e dos outros, criando e fortalecendo parâmetros, valores, aprendizados, ações que repercutem em 
um ciclo de reflexões voltadas a ações para uma vida comunitária mais humana e harmoniosa" (ABIB; SANTOS, 2016, p. 96).

Acrescenta-se ainda que os processos educacionais no âmbito da manifestação cultural, que envolvem o diálogo e estimulam a preservação e a promoção da cultura negra, potencializam vínculos que dão continuidade às manifestações culturais de resistência do povo negro na afirmação de sua cultura e identidade. Portanto, "a educação das relações étnico-raciais impõe aprendizagens entre brancos e negros, trocas de conhecimentos, quebra de desconfianças, projeto conjunto para construção de uma sociedade justa, igual, equânime" (BRASIL, 2004, p. 14).

É ainda merecido destacar, corroborando com Reis (2011, p.193), que o Brasil conserva comportamentos sociais para manutenção de preconceitos construídos desde o período colonial. A autora ainda ressalta que a discriminação "alimenta e reforça as representações sociais gerando um círculo vicioso do preconceito e da violência contra aquele que é o foco dos olhares estigmatizados". Contudo, conhecer o processo histórico do preconceito racial colabora na construção de uma nova percepção social da cultura negra e, ao mesmo tempo, possibilita a aceitação do outro.

Nesse sentido, resgatar e reconhecer a história do samba é fortalecer o movimento de resistência e afirmação do povo negro. Vale lembrar que o samba já foi muito perseguido por ser considerada uma expressão cultural da "ralé" (FERREIRA et al., 2003) e, mesmo após a abolição da escravidão, a estigmatização do negro ganhou nova densidade, um tanto negativa, visto que esse "processo não foi acompanhado por uma política na qual a população negra tivesse acesso à terra e à educação" (FERREIRA et al., 2003, p. 14).

Postas tais ponderações, levantou-se os seguintes questionamentos: mesmo com a tradição que o samba possui na sociedade brasileira, quais as concepções que os jovens têm sobre este estilo musical? E em que medida o samba pode levar a conscientizaçãodos jovens sobre a história de lutas e conquistas dos nossos antepassados? Mediante tais indagações, o objetivo do projeto de extensão era reconhecer o samba como uma das diversas manifestações de resistência do povo negro em nossa história enquanto afirmação de sua cultura e identidade, buscando desconstruir noções preconceituosas relacionadas às músicas de origem africana entre os jovens concluintes do Ensino Médio.

\section{DESENHO METODOLÓGICO}

Mediante a compreensão de que a metodologia se consolida como um conjunto de etapas organizadas com o intuito de contribuir na interpretação e explicação do objeto de investigação, o desenho metodológico dessa pesquisa teve como foco central uma abordagem qualitativa que, segundo Oliveira $(2005$, p.37) se caracteriza por ser um "processo de reflexão e análise da realidade através da utilização de métodos e técnicas para compreensão detalhada do objeto de estudo em seu contexto histórico ou segundo sua estruturação".

Pautando-se ainda que nas pesquisas de caráter qualitativo 0 investigador busca a tradição compreensiva ou interpretativa, uma vez que "as pessoas agem em função de suas crenças, percepções, sentimentos e valores" (ALVES-MAZZOTTI; GEWANDSZNAJDER, 2002, p.131), a intenção era compreender, a partir de significados e motivações, valores, etc. dos alunos, se estes viam o samba como fruto de uma das manifestações culturais de resistência do povo negro na afirmação de sua cultura e identidade.

Não menos importante, Tardif e Lessard $(2005$, p. 39) apontam que o espaço de inteligibilidade traçado depende do olhar teórico do pesquisador, gerando a "necessidade de estar atento às variações, às diferenças e às nuances que não deixam de aparecer quando se começa a estudar aquilo que os atores escolares realmente fazem".

Vale ainda lembrar, corroborando com Machado (1989) em uma investigação é indispensável se recorrer a pesquisas bibliográficas que discorram sobre a temática em questão, visto que é por meio dela que se toma conhecimento da literatura já publicada sobre o assunto e a evolução das respostas às questões levantadas.

Nessa perspectiva, em um primeiro momento, foi feita a seleção de uma instituição escolar estadual situada na cidade de Divinópolis (MG). A escolha do lócus de investigação levou em consideração a proximidade da Universidade para realização do projeto de extensão, oferta de turmas do 3 o ano do ensino médio no turno matutino $^{3}$ e a escola pertencer à localidade

${ }^{3}$ Disponibilidade da bolsista para realização do projeto de extensão. 
considerada periférica, pois como ressalta Ferreira et al. (2003, p. 17), "[...] a grande maioria da população negra vive nos bairros das periferias das cidades, nos povoados, vilas, encostas e favelas - regiões mais distantes do centro do poder, da distribuição da riqueza e do acesso à cultura e à comunicação".

Após o contato com a instituição escolar e com a supervisão, foram selecionadas, por indicação do professor de História, duas turmas do $3^{\circ}$ ano do Ensino Médio para serem contempladas com o projeto. De acordo com o docente, uma turma era mais disciplinada e atenta às questões postas em sala de aula, e a outra classe, em contrapartida, apresentava maiores dificuldades no que diz respeito à disciplina e atenção.

A seleção dessa série escolar pode ser explicada por dois motivos: a) contribuir para a formação identitária dos jovens, buscando a reafirmação de suas posturas enquanto agentes produtores de cultura e ideias, em um momento crucial de suas trajetórias escolares, isto é, a finalização do ciclo da educação básica; b) colaborar para que estes alunos pudessem ter um olhar crítico sobre situações de racismo, preconceito e intolerância em suas trajetórias pessoais e profissionais.

O projeto extensionista atingiu, desse modo, cerca de sessenta alunos, por meio de encontros quinzenais, que totalizaram ao final em 9(nove) momentos com os discentes. Em relação aos recursos metodológicos de caráter didáticos foram utilizados e mesclados por meio de aulas expositivas, atividades com recursos audiovisuais, uso de músicas, instrumentos musicais, rodas de conversa e debates, levando em consideração que "tais pedagogias precisam estar atentas para que todos, negros e não negros, além de ter acesso a conhecimentos básicos tidos como fundamentais para a vida integrada à sociedade, exercício profissional competente, recebam formação que os capacite para forjar novas relações étnico-raciais" (BRASIL, 2004, p. 17).

Cabe ressaltar que em grande parte dos encontros foi utilizado como forma de apresentação e apreensão dos conteúdos pelos alunos a roda de conversa, visando, além da dinamização dos momentos, uma maior integração dos discentes com as temáticas tratadas, isto é, procurava-se propiciar momentos em que estes se sentissem à vontade para expressar e falar suas opiniões, considerando que, conforme ressaltado por Melo (2011, p.01), "essa técnica apresenta-se como um rico instrumento para ser utilizado como prática metodológica de aproximação entre os sujeitos no cotidiano pedagógico".

Como forma de expor sucintamente os objetivos, as estratégias e as atividades realizadas no decorrer dos encontros do projeto de extensão, foi produzida uma tabela organizacional visando uma melhor execução do trabalho. 
Tabela 1. Atividades do projeto de extensão no ano 2018

\begin{tabular}{|c|c|c|}
\hline Objetivos & Estratégias & Atividades/Culminância \\
\hline $\begin{array}{l}\text { Reconhecer a diversidade } \\
\text { étnica brasileira e a origem } \\
\text { do estilo musical samba. }\end{array}$ & $\begin{array}{l}\text {-Ouvir, interpretar e debater sobre } \\
\text { a história da cultura africana e do } \\
\text { samba no Brasil; }\end{array}$ & $\begin{array}{l}\text {-Discussão sobre valores éticos e } \\
\text { morais e problematização da } \\
\text { importância do samba. }\end{array}$ \\
\hline $\begin{array}{l}\text { Classificar os sambas e suas } \\
\text { ramificações. }\end{array}$ & $\begin{array}{l}\text {-Conhecer os variados tipos de } \\
\text { samba e apresentar músicas do } \\
\text { samba e suas ramificações. }\end{array}$ & $\begin{array}{l}\text {-Conceituação } \\
\text { ramificações e divisão dos } \\
\text { estudantes para realização de uma } \\
\text { atividade didática }\end{array}$ \\
\hline $\begin{array}{l}\text { Problematizar a herança da } \\
\text { escravidão no Brasil. }\end{array}$ & $\begin{array}{l}\text {-Discutir o fator racial/étnico como } \\
\text { elemento na distribuição de } \\
\text { oportunidades. }\end{array}$ & $\begin{array}{l}\text {-Realização de uma roda de } \\
\text { conversa com os alunos sobre a } \\
\text { desigualdade racial no país. }\end{array}$ \\
\hline $\begin{array}{l}\text { Compreender os sambas- } \\
\text { enredos utilizados pelas } \\
\text { escolas de samba ao longo da } \\
\text { história e os atuais. }\end{array}$ & $\begin{array}{l}\text {-Apresentar composições dos } \\
\text { sambas-enredos que retratem a } \\
\text { situação do negro na sociedade } \\
\text { brasileira. }\end{array}$ & $\begin{array}{l}\text {-Discussão e interpretação das } \\
\text { canções carnavalescas produzidas } \\
\text { ao longo da história. }\end{array}$ \\
\hline $\begin{array}{l}\text { Comparar os diversos tipos } \\
\text { de samba no processo } \\
\text { histórico brasileiro. }\end{array}$ & $\begin{array}{l}\text {-Proporcionar aos alunos } \\
\text { oportunidade de valorizar o samba } \\
\text { como presença viva da expressão } \\
\text { cultural afro-brasileira. }\end{array}$ & $-R$ \\
\hline Cant & $\begin{array}{l}\text {-Problematizar as principais } \\
\text { ramificações do estilo musical: } \\
\text { samba. }\end{array}$ & $\begin{array}{l}\text {-Permitir que os alunos saibam } \\
\text { identificar os estilos musicais do } \\
\text { samba. }\end{array}$ \\
\hline $\begin{array}{l}\text { Orientação para os trabalhos } \\
\text { da "Semana da Consciência } \\
\text { Negra". }\end{array}$ & $\begin{array}{l}\text {-Desenvolver uma atividade com os } \\
\text { alunos buscando compreender o } \\
\text { que foi realizado e estudado ao } \\
\text { longo do projeto de extensão. }\end{array}$ & $\begin{array}{l}\text {-Divisão das ramificações do samba } \\
\text { (grupos de alunos) para } \\
\text { apresentação na atividade da } \\
\text { semana de consciência negra. }\end{array}$ \\
\hline $\begin{array}{l}\text { Execução dos trabalhos na } \\
\text { "Semana da Consciência } \\
\text { Negra". }\end{array}$ & -Apresentar trabalhos realizados. & $\begin{array}{l}\text {-Exposição dos trabalhos } \\
\text { desenvolvidos pelos alunos. }\end{array}$ \\
\hline Finalização do projeto. & $\begin{array}{l}\text {-Estabelecer um diálogo com os } \\
\text { alunos a respeito do projeto } \\
\text { desenvolvido ao longo do ano. }\end{array}$ & $\begin{array}{l}\text {-Roda de conversa sobre o projeto } \\
\text { de extensão desenvolvido. }\end{array}$ \\
\hline
\end{tabular}

Fonte: Autoras (2019)

\section{ANÁLISE DOS RESULTADOS}

Ao considerar que os processos educacionais são vistos como relações humanas de trocas e aprendizagens, de maneira que a memória e a identidade são essenciais na formação dos indivíduos e nos espaços de interação com as pessoas, o projeto em questão buscou reconhecer o samba como uma das manifestações culturais de resistência do povo negro na afirmação de sua cultura e identidade, desmistificando noções preconceituosas relacionadas às músicas de origem africana. Nesse sentido, a intenção das atividades do projeto vai ao encontro do que é defendido por Abib e Santos (2016, p. 94):

[...] encontrarem meios $\mathrm{e}$ espaços com o intuito de promover o diálogo com os demais jovens, para que os laços humanos sejam construídos e para que aconteça o que Freire preconiza: uma educação comprometida com a conscientização, transformando-os em sujeitos participativos com sua comunidade.

Ademais, pautado pelo apoio governamental da Lei no 10.639 , que define como obrigatório trabalhar tais temáticas, Fernandes (2005) salienta a relevância do ensino de História da África no currículo da educação básica, inclusivo para reforçar o papel da escola de combate ao preconceito e à discriminação.

Nessa perspectiva, as atividades do projeto se iniciaram no dia 13 de junho de 2018, com uma abordagem inicial pautada no "Reconhecimento da diversidade étnica brasileira, a origem da palavra 'samba' e a biografia de compositores que marcaram significativamente o início do estilo musical no Brasil". Foi realizada uma breve abordagem com 
o intuito de expor os objetivos do projeto e, em seguida, foram apresentadas as temáticas propostas, destacando as diversidades e manifestações da cultura de resistência do povo negro na historia do Brasil, bem como na reafirmação de seus costumes e identidade.

Inicialmente sobre as conceituações expostas e que posteriormente seriam trabalhadas com os discentes, cabe à ressalva que "a questão étnico-racial ultrapassa o âmbito estrito do rechaço ao racismo e à discriminação racial, a partir do marco histórico da Constituição Federal de 1988, que torna relevante a intervenção na educação" (PETIT, 2016, p.661). Acrescenta-se que se atentou em apresentar aos discentes a contribuição do povo negro, a partir da valorização da memória social e musical do samba, mostrando ainda a situação de marginalização vivenciada pelos negros. Foi propiciado ainda, aos alunos, o entendimento de visões eurocêntricas e preconceituosas ligadas às músicas de linhagem africana. Uma vez que, conforme Fernandes (2005, p.380):

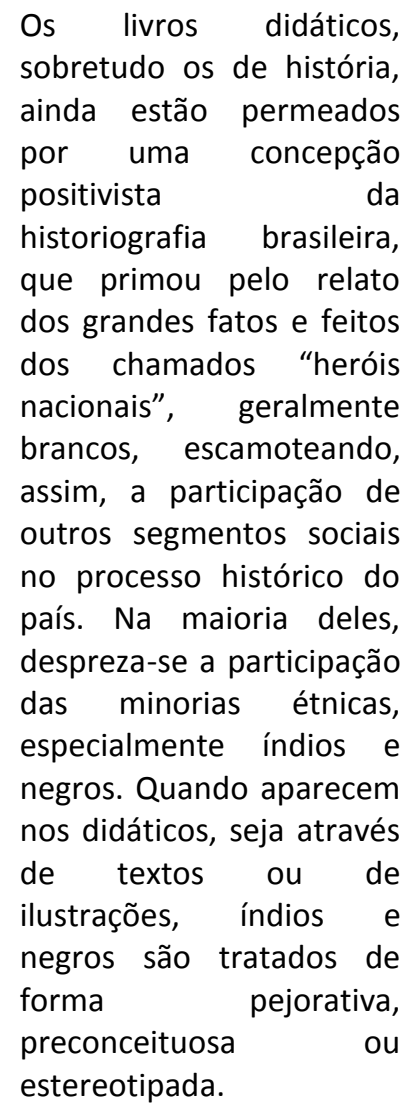

Buscando romper com essa visão positivista da historiografia brasileira, sentiu-se a necessidade de levantar a discussão sobre a condição de ser negro no Brasil, que, sobretudo nega sua participação crucial na formação da sociedade histórica do país. Foi abordada a questão da objetificação do escravo frente à escravidão instaurada no Brasil (cultura canavieira, na extração aurífera, no desenvolvimento da pecuária e no cultivo do café), em diferentes momentos de nosso processo histórico (FERNANDES, 2005).

Não menos importante, foi posto em destaque o reconhecimento da interligação da produção cultural com o contexto histórico e cultural de determinado grupo social em questão. Vale a ressalva que, após a finalização das atividades do primeiro encontro, observou-se uma boa participação e aceitação favorável sobre a ideia do projeto em ambas as turmas selecionadas para a contemplação dos trabalhos extensionistas.

Após esse momento inicial, os encontros seguintes seguiram uma espécie de linha do tempo para contribuir e levar os alunos à formação de um raciocínio cronológico e lógico, com o intuito de uma melhor compreensão das classificações e respectivas ramificações do samba. Foi contada a história do samba desde suas origens, como a consolidação do samba de roda na Bahia e sua posterior expansão e desenvolvimento ao longo do Brasil. Dessa forma, em cada encontro eram retratados momentos importantes e relevantes da trajetória negra na história do país, buscando ilustrar o samba e sua história de resistência e reafirmação de uma cultura sucumbida por ideias eurocêntricas e alvos de preconceito e depreciação. Vale lembrar que o projeto considerou que:

[...] com o avanço de novos estudos culturais e sobre a diversidade, a escola precisa apoderar-se dessas discussões e leválas para seu interior, debatendo, com os gestores, educadores, educandos, corpo técnico e administrativo, questões tão atuais que, às vezes, nos pegam desprevenidos. Ou seja, esses assuntos precisam estar na pauta de discussão de toda unidade escolar (ONOFRE, 2008, p. 105).

No segundo encontro com os alunos, foi contada a história do samba desde suas origens, como samba de roda e seu posterior desenvolvimento. Foi retratado ainda o período 
de 1850 e o intenso tráfico interprovincial de negros provenientes em grande escala de províncias do norte e do Rio de Janeiro. A intenção era mostrar que havia a influência de outros estilos musicais no território como o Choro e o Lindu, de forma que foram se diversificando e ramificando a vários e distintos "tipos de samba". A letra de samba de Zé Kétti (1956), "A voz do morro", propiciou traçar alguns aspectos dessa historia, considerando que:

Cantar e contar a historia do samba é fortalecer um movimento de resistência e de afirmação do povo negro, que, a partir das batidas do tambor das rodas de candomblé e capoeira da Bahia, estendeu-se pelo Brasil. No Rio de Janeiro, por meio das casas tradicionais das 'tias' baianas, esse povo que, após a abolição do trabalho escravo, exerceu as mais variadas atividades profissionais, trabalhando de sol a sol e morando nos cortiços do centro da cidade, tinha o samba como espaço de interação, sociabilidade e diversão (FERREIRA; SANTOS; CARDOSO, 2004, p. 28).

Após tais explicações foram apresentadas aos alunos as principais e mais influentes ramificações do samba: Enredo, Breque, Rock, Partido Alto, Exaltação, Choro, Reggae e a Bossa Nova. O objetivo era ilustrar o contexto, os seus compositores notáveis e as mais evidentes marcas de cada ramificação, de modo a conseguir um melhor entendimento sobre a temática. Percebeu-se um bom entrosamento da maior parte dos estudantes e muitos reconheceram a importância desse assunto que abarcava 0 respeito à cultura negra e suas manifestações culturais, principalmente quando foi mostrado aos alunos dois dos principais instrumentos usados no samba, cavaquinho e o pandeiro.

É importante salientar que no decorrer dos encontros ministrados era recorrente, por meio da problematização do tema ordem do dia, que houvesse um compartilhamento satisfatório de conhecimento e saberes acumulados, bem como experiências pessoais sobre os assuntos postos em discussão. Isso porque, segundo Dayrell (2002), é relevante o respeito às diferenças que os discentes carregam consigo:

Uma outra forma de compreender esses jovens que chegam à escola e apreendê-los como sujeitos sócio-culturais. Essa outra perspectiva implica em superar a visão homogeneizante e estereotipada da noção de aluno, dando-lhe um outro significado. Trata-se de compreendê-lo na sua diferença, enquanto indivíduo que possui uma historicidade, com visões de mundo, escalas de valores, sentimentos, emoções, desejos, projetos, com lógicas de comportamentos e hábitos que lhe são próprios (DAYRELL, 2002, p. 141).

Pôde-se observar que em resposta a essas atividades de conversação proposta aos alunos no decorrer dos encontros, obteve-se em ambas as turmas um entrosamento e levantamento de discussões interessantes, abrangendo debates um tanto significativos sobre a contribuição do negro para a formação da cultura brasileira, indo ao encontro do que é proposto nas Diretrizes Curriculares Nacionais para a Educação das Relações Étnico-Raciais:

Precisa, o Brasil, país
multi-étnico
pluricultural, e
organizações escolares em
que todos se vejam
incluídos, em que lhes seja
garantido o direito de
aprender e de ampliar
conhecimentos, sem ser
obrigados a negar a si
mesmos, ao grupo
étnico/racial a que
pertencem e a adotar
costumes, idéias e
comportamentos que lhes
são adversos (BRASIL,
2004, p. 18).

Como exemplificação desse entrosamento e atividade de conversação 
explicitada, pode se colocar em pauta o encontro que foi debatido sobre "A problematização da herança da escravidão e reconhecimento das estratégias representativas e desigualdades sócio-raciais no Brasil". O debate foi iniciado a partir de algumas questões levantadas sobre a temática e a interpretação da letra da música de Nelson Sargento, produzida em 1978: "Agoniza, mas não morre". Essa canção é caracterizada com umas das que melhor representa a resistência cultural do samba carioca, considerado um hino dos sambistas brasileiros.

Após a apresentação da música referida e problematização da letra, uma aluna se pronunciou acerca de uma situação de racismo que havia acontecido na escola há pouco tempo, declarando: "Estou inconformada com a situação, a escola não fez nada, a supervisora ficou sabendo, mas não quis chamar a polícia, para não chamar a atenção da escola". Ainda de acordo com a mesma aluna, o aluno que havia cometido o referido preconceito frente a outro estudante não foi punido pela escola.

A partir deste comentário teve início um debate acalorado entre os outros alunos sobre o racismo ainda vigente na sociedade brasileira. Essa situação leva-nos a reconhecer a necessidade de discutirmos e propiciarmos:

[...] uma educação antiracista que presa pelo respeito à diferença, à diversidade. Ela não pode isentar-se do compromisso com os mais necessitados e fragilizados por um sistema desumano e preconceituoso. Educar, respeitando as diferenças, requer mais do que 0 cumprimento das obrigações curriculares, exige uma postura ética e valorativa diante da cultura dos afrodescendentes, que continuam sofrendo discriminações nos espaços escolares (ONOFRE, 2008, p.104)

O episódio revela ainda como a realização de projetos extensionistas que discutem a temática da cultura africana nas escolas pode amenizar casos de racismo e preconceito que acontecem para além dos muros da escola, uma vez que, segundo Munanga (2010, p.02):
[...] o fenômeno chamado racismo tem uma grande complexidade, além de ser muito dinâmico no tempo e no espaço. Se ele é único em sua essência, em sua história, características e manifestações, ele é múltiplo e diversificado, daí a dificuldade para denotá-lo, ora através de uma única definição, ora através de uma única receita de combate.

Cabe ainda ressaltar que durante este mesmo encontro, houve uma grande adesão, por parte dos alunos, da importância de discutir o racismo, florescendo uma série de questionamentos e conclusões que perpassavam a abordagem tratada na música "Agoniza, mas não morre". Isso possibilitou que alguns estudantes se sentissem confortáveis para expor relatos de indignação acerca de algumas situações vivenciadas no cotidiano, no ambiente escolar ou fora dele. Os estudantes também mencionaram notícias midiáticas, recentes ou não, sobre o racismo, ressaltando que algumas causam depreciação do povo negro no país. Nesse aspecto,

A relevância do estudo de
temas decorrentes da
história e cultura afro-
brasileira e africana não se
restringe à população
negra, ao contrário, diz
respeito a todos os
brasileiros, uma vez que
devem educar-se
enquanto cidadãos
atuantes no seio de uma
sociedade multicultural e
pluriétnica, capazes de
construir uma nação
democrática (BRASIL,
2004, p. 17).

Dando continuidade às atividades extensionistas, o encontro seguinte teve como objetivo principal levar os alunos a compreenderem os sambas-enredos utilizados pelas escolas de samba ao longo da história e, ao mesmo tempo, conhecerem os sambas enredos atuais, inclusive no que tange às denúncias sociais presentes nas composições. Foi realizada uma contextualização histórica do samba-enredo, revelando como as canções eram marcadas 
constantemente por formas de delação das mazelas da sociedade brasileira. Tanto que "em 1940, Getúlio Vargas censurou o samba, porque as letras tinham forte apelo à reflexão social" (FERREIRA; SANTOS; CARDOSO, 2003, p. 29), o que demonstra nitidamente que 0 samba questionava os poderes vigentes da época.

Em um segundo momento deste encontro, com o auxílio metodológico de slides ilustrativos, tratou-se de apresentar as principais músicas e seus respectivos contextos socioculturais que fizeram história nos carnavais brasileiros. Posteriormente, foram expostas algumas das composições de sambas enredos que marcaram o carnaval de 2018, mostrando aos alunos como as escolas de samba Mangueira, Beija-Flor e Tuiuti abordaram o debate político nas ruas.

Contudo, deu-se mais destaque à escola de samba do Paraíso do Tuiuti, visto que esta trouxe, ao longo de seu desfile pelas ruas cariocas, o trabalho como centro e a longa duração da exploração da classe trabalhadora, apresentando a escravidão através de críticas sociais. Ainda foi discutido com os estudantes o samba enredo tema da escola: "Meu Deus, Meu Deus, Está Extinta a Escravidão?", propondo um debate que se remeteu aos 130 anos da Lei Áurea, completados no ano de 2018.

Dando continuidade aos trabalhos extensionistas e como previsto no cronograma de execução do projeto de extensão, foi realizada uma gincana cultural com os alunos, tendo como fim fazer com que eles comparassem os diversos tipos de samba no processo histórico-social brasileiro. A intenção, também, era que os estudantes pudessem valorizaro samba como expressão cultural e identitária. Essa atividade de caráter pedagógico visou:

Proporcionar à comunidade escolar oportunidade de vivenciar atividades pedagógicas lúdicas e significativas que os levem à sensibilização, ao conhecimento e à valorização do samba como presença viva da expressão cultural AfroBrasileira e a inserção dele no processo histórico brasileiro (FERREIRA; SANTOS; CARDOSO, 2004, p.47).
Desse modo, foi orientado que os grupos de alunos fizessem a leitura das letras das canções pré-selecionadas e, em seguida, discutissem entre os componentes a interpelação entre a composição da música de samba, o contexto histórico e os objetivos do compositor. Ao final da gincana ainda foi proposta uma atividade que se consolidou na produção de uma letra de samba. $O$ objetivo era que os estudantes produzissem uma letra que mostrasse um símbolo de resistência às mazelas da sociedade brasileira, inclusive no tocante às minorias. Segue a composição de uma letra de samba desenvolvida por um grupo de alunos:

\section{Preto Guerreiro}

Preto se você quer ser branco

Pra mim não tem valor

Deixe de lado essa loucura

E vê se honra sua cor

Pense no sofrimento da sua gente

Racismo, escravidão, açoite, grito urgente

Nas viagens angustiantes dos navios negreiros

Celeiros humanos

Eles foram guerreiros!

Tudo que esse povo sofreu

A terra ensanguentada me contou

Foram anos de sofrimento

E agora eu te pergunto, acabou?

Prosseguindo as atividades, um encontro foi pautado no seguinte tema: "Cantar a história do samba". A princípio, relembrou-se, juntos aos alunos, o conteúdo discutido até o presente momento do projeto, por meio da recordação dos pontos principais que diziam respeito à compreensão da história do samba e formação de suas ramificações. Em um segundo momento, foram discutidos recortes específicos da história do samba no Brasil, objetivando destacar os principais aspectos que regem a formação desse estilo musical em território brasileiro, demarcando algumas das principais ramificações do estilo musical (Samba-choro; Samba Canção; Samba de breque; Sama exaltação e samba de partido alto).

Como forma de finalização das atividades, com o auxílio do professor de História da escola e em consonância à semana sociológica desenvolvida pela própria escola, foi estabelecido que os alunos realizassem uma atividade final para ser apresentada no dia 20 de novembro de 
2018, dia da Consciência Negra, para a comunidade escolar. Tratava-se de uma exposição a respeito de uma determinada ramificação do samba, sendo pré-estabelecida anteriormente para os alunos. Cada uma das duas turmas ficou com um tipo de ramificação de samba, sendo: um grupo de uma turma se encarregou de expor o samba-enredo e outro o samba-raiz (por ser uma turma com maior número de alunos) e outro grupo se encarregou do samba-exaltação.

A atividade final deveria contemplar o contexto histórico do referido samba selecionado, as principais composições e autores. Além disso, os estudantes foram orientados sobre a forma de ilustração das salas de aula para a exposição à comunidade escolar, recorrendo a recursos icnográficos que ilustrassem o tipo de ramificação selecionado. A atividade obteve resultados satisfatórios; os alunos se empenharam em realizar o trabalho de maneira criativa e houve muito empenho, demarcando precisamente cada um dos pontos selecionados. Pode-se observar, também, um expressivo uso da criatividade dos estudantes na decoração das salas, utilizando imagens e cenários que demarcavam significativamente o samba.

No último encontro do projeto, a intenção era receber um retorno dos alunos quanto às atividades realizadas. Ambas as turmas apontaram a relevância das temáticas trabalhadas, enfatizando a valorização de uma cultura que não é trabalhada efetivamentenas escolas, ou mesmo trabalhada secundariamente. Uma aluna relatou que: "O projeto visa ensinar coisas que a própria escola não ensina e também a desenvolver a gente pessoalmente, culturas que a gente nem imaginava ter. É importante a gente saber a nossa cultura, as nossas raízes."

Neste encontro final os alunos expuseram como ponto positivo do projeto as explicações e contextualizações históricas do racismo estrutural na sociedade brasileira, assim como o patriotismo exaltado de maneira evidente em algumas letras de samba. Os estudantes ainda salientaram o quanto seria relevante a continuidade do projeto com outras turmas da educação básica, uma vez que permitiu e contribuiu para a realização de discussões e debates acerca do samba, através de canções desconhecidas até o momento por eles. Segundo uma discente:

"Eu gostei muito do trabalho, como já foi dito, eu acho que é muito importante trabalhar o racismo nas escolas, porque isso é um tema muito pouco debatido, $e$ eu gostei muito de conhecer a história do samba, principalmente nosso samba, que foi o samba exaltação, me fez realmente conhecer um pouco mais do Brasil e da questão do patriotismo $e$ enriqueceu bastante esse projeto e como eu falei se for continuar melhorar só a questão da didática, tentar trazer coisas que façam os alunos interagirem mais no projeto, mas na questão da apresentação e de tudo eu gostei muito, foi muito bom."

No entanto, é merecido destacar que uma das temáticas mais levantadas pelos alunos ao longo dos encontros diz respeito ao racismo. Em mais de um encontro ficou nítido o interesse dos estudantes por discutir como o racismo está presente na sociedade brasileira, inclusive dentro da própria escola, o que justifica a relevância de estudos e trabalhos que retratem as relações raciais e sociais nas instituições escolares. Vale ainda lembrar que:

Combater o racismo,
trabalhar pelo fim da
desigualdade social e
racial, empreender
reeducação das relações
étnico-raciais não são
tarefas exclusivas da
escola. As formas de
discriminação de qualquer
natureza não têm o seu
nascedouro na escola,
porém o racismo, as
desigualdades
discriminações correntes
na sociedade perpassam
por ali (BRASIL, 2004, p.
14).

Ainda sobre a relevância do projeto extensionista, outro aluno revelou:

"Eu gostei muito do projeto $e$ achei muito interessante, porque 0 
racismo tem que ser debatido, tem que ser um assunto debatido $e$ discutido no Brasil, né?! Por ser, por ter sido 300 anos de escravidão, aliás, mais né?! É claro que isso deixou marcas, muito fortes na cultura brasileira, então tem que ser debatido e nada melhor do que por meio do samba né?! Que é um instrumento tão bacana, vindo, proveniente $d a$ cultura africana depois miscigenada, misturada com a brasileira, como eu disse, é, seria legal introduzir a história da África no projeto $e$ apresentar melhor."

Interessante ressaltar que uma aluna, em seu depoimento, expôs que o projeto abordou assuntos e discussões que a escola não havia trabalhado até aquele momento, destacando ainda que ele possibilitou um desenvolvimento pessoal e intelectual dos estudantes no que diz respeito ao conhecimento de culturas não estudadas ao longo da educação básica. Nesse sentido,

A escola, enquanto espaço de descobertas, troca de experiências

aprendizados diversos, necessita abrir-se para a realidade dos educandos $\mathrm{e}$ da comunidade. Essa realidade se traduz naquilo que consideramos de suma importância para a complementação do currículo escolar: a inserção de saberes, vivências e manifestações culturais que acontecem fora dos muros escolares. (ONOFRE, 2008, p.106)

Entretanto, para que tais temáticas sejam trabalhadas efetivamente nas salas de aula da educação básica, será necessário a implementação efetiva de um currículo escolar que atribua espaços igualitários a essas questões. "Numa visão crítica, podemos afirmar que as práticas curriculares reproduzem o saber de um grupo dominante que manipula o conhecimento e os saberes com base na afirmação de uma hegemonia racional que coloca em desvantagem as minorias desprivilegiadas dos bens culturais" (ONOFRE, 2008, p.106).

Mediante os relatos discentes, ficou evidente que discutir a cultura negra é ressignificar representações positivas sobre a história dos africanos, sua cultura, sua corporeidade e sua estética, uma vez que, ao pensar em "negros", como afirma Silva (2015, p. 17-19), "pode-se ter várias conotações como 'preconceito', 'cultura africana', 'carnaval', 'virilidade' ou até mesmo a 'religião de candomblé".

Acrescenta-se que trabalhos desta natureza podem colaborar para resgatar a importância e respectiva influência dos negros na constituição do território nacional: "é inegável a expressiva participação africana na formação da sociedade brasileira, assim como é inegável que a condição inicial de escravo deixaria marcas douradoras, demarcando lugares sociais a serem ocupados por esta população e seus descendentes" (SANTOS, 2010, p. 2).

Portanto, diante das percepções na realização do projeto de extensão, fica evidente que debater o preconceito racial nas escolas, por meio do samba ou outros recursos metodológicos, pode colaborar significativamente na construção de uma nova percepção social da cultura negra, permitindo, assim, a aceitação do outro, em uma sociedade marcada pela diversidade.

\section{CONSIDERAÇÕES FINAIS}

A promoção de atividades de um Projeto de Extensão dessa natureza é, sem dúvidas, um desafio aos profissionais da educação básica, visto que a sociedade está impregnada de noções um tanto deturpadas de temáticas que perpassam as Relações Étnico-Raciais. Dessa forma, debater a história do povo negro no Brasil, assim como seu papel relevante e crucial para a constituição da identidade e formação do povo brasileiro, ressalta a valorização das diferenças, o rompimento de preconceitos, bem como visões negativas sobre os negros.

Notou-se a importância de re (contar) a história da formação territorial do Brasil a partir da presença de outros atores que a compuseram. Nessa perspectiva, o samba foi um meio de conscientização dos jovens sobre a história de lutas e conquistas dos nossos antepassados, 
colaborando para que os estudantes pudessem se posicionar para além dos muros da escola.

Foi demonstrado que discutir o preconceito racial possibilitou e colaborou para que os alunos pudessem constituir uma nova e diferenciada percepção social da cultura afrodescendente, tão importante e essencial na formação cultural, social e histórica da sociedade brasileira e, neste aspecto, os objetivos propostos no projeto de extensão foram alcançados. Cabe ressaltar que os alunos puderam traçar um novo olhar a respeito da história e herança do povo negro, considerando a participação destes povos na formação do território nacional.

Respondendo às indagações iniciais postas no projeto desenvolvido, mesmo com a tradição que o samba possui na sociedade brasileira, os jovens não possuem conhecimento aprofundado sobre este estilo musical, embora tenham sido receptivos às canções apresentadas de demonstraram interesse na problematização que elas buscavam difundir em seu contexto de criação.

Contudo, mesmo desconhecendo essas canções, os estudantes concluintes da educação básica se identificaram sobre a história de lutas e conquistas dos negros ao longo do processo de formação sócio-histórica do Brasil, inclusive, destacando a importância de a escola se empenhar em trabalhar e discutir temáticas que abordem a cultura africana. Viu-se, assim, a necessidade, relatada pelos próprios envolvidos no projeto, da continuidade de projetos dessa natureza, principalmente na educação básica, em que se espera a discussão da valorização da cultura afrodescendente, processo lento e gradual em curso, que possibilite o conhecimento da história de lutas e conquistas dos negros.

\section{AGRADECIMENTOS}

Os agradecimentos se destinam ao: Programa de Apoio a Projetos de Extensão (PAEx) através do financiamento da bolsa de apoio a Projetos de Extensão; apoio assistencialista e técnico da escola estadual de Divinópolis-MG, bem como ao professor de História da referida instituição escolar.

\section{REFERÊNCIAS}

ABIB, P. R. J.; SANTOS, N. C. P. Zambiapunga: cultura popular e processos educacionais baseados na construção e na afirmação de identidades. Educação em Foco, v.19, n. 28., p. 75-101, mai. /ago. 2016.

ALVES-MAZZOTTI, A. J.; GEWANDSZNAJDER, F. 0 método nas ciências naturais e sociais: pesquisa quantitativa e qualitativa. 2.ed. São Paulo: Pioneira Thomson Learning, 2002.

BRASIL. Ministério da Educação. Diretrizes Curriculares Nacionais para a Educação das Relações Étnico Raciais e para oEnsino de Historia e Cultura Afro-Brasileira e Africana. Brasília: MEC, $2004 . \quad$ Disponível em:http://portal.inep.gov.br/documents/186968 /484184/Diretrizes+curriculares+nacional+para+a +educa\%C3\%A7\%C3\%A30+das+rela\%C3\%A7\%C3 \%B5es+\%C3\%A9tnico-

raciais+e+para+o+ensino+de+hist\%C3\%B3ria+e+cultura+afro-brasileira+e+africana/f66ce7cae0c8-4dbd-8df3-4c2783f06386?version=1.2.

Acesso em: 31 jul. 2019.

DAYRELL, J. A escola como espaço sócio-cultural. In: DAYRELL, J. (Org.) Múltiplos olhares sobre educação e cultura. Belo Horizonte: Editora da UFMG, 2001. p. 136-161.

FERNANDES, J. R. O. Ensino de História e diversidade cultural: desafios e possibilidades. Cad. Cedes, Campinas, vol. 25, n. 67, p. 378-388, set./dez. $2005 . \quad$ Disponível em: http://www.scielo.br/scielo.php?script=sci_arttex t\&pid=S0101-

$32622005000300009 \& \operatorname{lng}=p t \&$ tIng=pt. Acesso em: 31 jul. 2019. https://doi.org/10.1590/s0101$\underline{32622005000300009}$

FERREIRA, E. L.; SANTOS, E. D.; CARDOSO, M. A. Contando a história do samba. Belo Horizonte: Mazza Edições, 2003.

MACHADO, A. M. N. Pesquisa escolar: uma questão para resolver. 1989. Dissertação (Mestrado em Biblioteconomia) - Faculdade de Biblioteconomia - PUCCAMP, Campinas, 1989.

MELO, M. C. H. ; CRUZ, G. de C. Roda de conversa: Uma proposta metodológica para a construção de um espaço de diálogo no Ensino Médio. In: Imagens da Educação, v. 4, n. 2, p. 3139, $2014 . \quad$ Disponível em: http://periodicos.uem.br/ojs/index.php/Imagens Educ/article/view/22222. Acesso em: 07 jul. 
2019.

https://doi.org/10.4025/imagenseduc.v4i2.22222

MUNANGA, K. Teoria social e relações raciais no Brasil contemporâneo. Cadernos Penesb, Niterói, 2010 . Disponível em: http://www.mprj.mp.br/documents/20184/1726 82/teoria_social_relacoes_sociais_brasil_contem poraneo.pdf. Acesso em 15 jul. 2019

OLIVEIRA, M. M. Como fazer pesquisa qualitativa. 2.Ed.Rio de Janeiro: Vozes, 2005.

ONOFRE. J. A. Repensando a questão curricular: caminho para uma educação anti-racista. Práxis Educacional, Vitória da Conquista v. 4, n. 4, p. 103-122, jan./jun. 2008.

PETIT, S. H. Práticas Pedagógicas para a Lei $\mathrm{N}^{\circ}$ 10.639/ 2003: A criação de nova abordagem de formação na perspectiva das africanidades. Educ. Foco, Juiz de Fora, v.21, n.3, 657-684,set. / dez. $2016 . \quad$ Disponível em: https://periodicos.ufjf.br/index.php/edufoco/arti cle/view/19874. Acesso em: 07 jul. 2015 https://doi.org/10.22195/2447-

$\underline{5246 v 21 n 320163194}$

REIS, L. M. Estigma, preconceito de cor e violência nas escolas. In: FRAGA, F. C. B; ROSA, J. H. A; ARÃO, L. Dez olhares sobre: juventude e cultura. Belo Horizonte: Fundação Guimarães Rosa - FGR. 2011, p. 193-197.

SANTOS, L. Saberes e práticas em Redes de Trocas: a temática africana e afro-brasileira em questão. 2010. 334f. Tese (Doutorado em Educação) - Universidade Federal de Minas Gerais, Belo Horizonte, 2010

SILVA, E. F. da. Educação, identidade e relações étinico-raciais: 5o caderno didático da Especialização UNIAFRO. 1. ed. Mossoró: Ed, Ufersa, 2015.

TARDIF, M.; LESSARD, C. O Trabalho Docente: elementos para uma teoria da docência como profissão de interações humanas. Petrópolis, Rio de Janeiro: Vozes, 2005. 